\title{
First detection of tidal behaviour in polar mesospheric water vapour by ground based microwave spectroscopy
}

\author{
K. Hallgren and P. Hartogh \\ Max Planck Institute for Solar System Research, Katlenburg-Lindau, Germany \\ Correspondence to: K. Hallgren (hallgren@mps.mpg.de) \\ Received: 3 October 2011 - Published in Atmos. Chem. Phys. Discuss.: 29 November 2011 \\ Revised: 6 March 2012 - Accepted: 14 March 2012 - Published: 24 April 2012
}

\begin{abstract}
Mesospheric water vapour has been observed above ALOMAR in northern Norway $\left(69^{\circ} \mathrm{N} 16^{\circ} \mathrm{E}\right)$ by our group since 1995 using a $22 \mathrm{GHz}$ ground based microwave spectrometer. A new instrument with higher sensitivity, providing a much better time resolution especially in the upper mesosphere, was installed in May 2008. The time resolution is high enough to provide observations of daily variations in the water vapour mixing ratio. We present the first ground based detections of tidal behaviour in the polar middle atmospheric water vapour distribution.

Diurnal and semidiurnal variations of water vapour have been observed and due to the long chemical lifetime of water they are assumed to be caused by changing wind patterns which transport water-rich or poor air into the observed region. The detected tidal behaviour does not follow any single other dynamical field but is instead assumed to be a result of the different wind components.

Both the diurnal and semidiurnal amplitude and phase components are resolved. The former shows a stable seasonal behaviour consistent with earlier observations of wind fields and model calculations, whereas the latter appears more complex and no regular behaviour has so far been observed.
\end{abstract}

\section{Introduction}

The dynamical behaviour of the polar middle atmosphere is important for the global circulation and in order to correctly model it a comprehensive knowledge of all the involved processes is needed.
Atmospheric tides are known to affect the gravity waves which are an important component for the dynamical behaviour in the middle atmosphere (Fritts and Vincent, 1987; Wang and Fritts, 1991). It is therefore of interest to understand all aspects of the tidal behaviour in the Mesosphere and Lower Thermosphere (MLT) region. Tidal behaviour in temperature and the different wind components in the polar regions are commonly observed by satellite (Forbes and $\mathrm{Wu}$, 2006; Manson et al., 2002a) as well as by ground based instruments (Manson et al., 2002b; Lübken et al., 2011). A monthly mean climatology has also been published in the case of tides in the wind fields (Portnyagin et al., 2004). The winds fields are commonly observed with MF and meteor radars which return information about the altitude range 80 $100 \mathrm{~km}$, and sometimes also with incoherent scatter radars which extend the altitude range to $120 \mathrm{~km}$. Observations of tides in temperature was done with the UARS satellite (Forbes and $\mathrm{Wu}, 2006$ ) and recently a ground based LIDAR was also able to detect them (Lübken et al., 2011). Both ground and space based instruments have their strengths and weaknesses and complement each other well. While a ground based instrument is continuously observing the same spot in the sky and therefore able to create a detailed view of daily variations (constrained by the instrument sensitivity) the corresponding capabilities of an orbiting instrument are severely hampered by the orbital parameters which usually constrain the observation of any given location to a fixed or slowly varying local time. On the other hand, the ground based instrument needs information about global scale waves from satellites to be able to draw conclusions about the observed variations. Ground based microwave spectroscopy is a well-established technique which has proven to be useful 
for observations of the water vapour mixing ratio (WVMR) on different time scales, from long term trends and seasonal behaviour to isolated events such as sudden stratospheric warmings (Hartogh and Jarchow, 1995; Nedoluha et al., 1996; Seele and Hartogh, 2000; Hartogh et al., 2010). The chemical lifetime of water vapour in the middle atmosphere is on the order of days to weeks (depending on altitude) which is similar to the characteristic dynamical time scale of interest and can therefore be used as a tracer molecule (Brasseur and Solomon, 1998). In contrast to tidal behaviour in the dynamical fields, almost no information of the behaviour of atmospheric tracers such as water vapour exist to a large extent due to the observational difficulties. Haefele et al. (2008) report of daily variations in the WVMR measured with a ground based microwave spectrometer in the Alps. They compare these variations to chemistry-climate models (SOCOL, MSDOL and LMDz) and conclude that the variations in the stratosphere are mainly induced by meridional advection and in the mesosphere by vertical advection. At high latitudes such as the polar regions the tidal amplitudes are generally understood to be smaller than at the equator due to the much weaker solar excitation. To the best of the authors knowledge this is the first time diurnal (and semidiurnal) variations of water vapour at a polar location have been observed and described.

\section{Instrument}

To retrieve the tidal variations in the WVMR in the middle atmosphere we use a ground based microwave spectrometer. Our observations of the polar, middle atmospheric WVMR by ground based spectroscopy at the ALOMAR observatory in northern Norway $\left(69.16^{\circ} \mathrm{N}, 16.00^{\circ} \mathrm{E}\right)$ started with the successful WASPAM instrument (Wasserdampf- und Spurengasmessungen in der Atmosphäre mit Mikrowellen), described in Hartogh and Jarchow (1995). Observations from WASPAM have been used to gain insight in the annual variability of water vapour as well as its behavior during sudden stratospheric warmings and the quasi 5-day wave (Seele and Hartogh, 1999, 2000; Sonnemann et al., 2008; Hartogh et al., 2010). A new instrument, cWASPAM (cooled-WASPAM), was installed at ALOMAR in May 2008 and has been running continuously ever since, with the exception of a few maintenance stops. cWASPAM has a higher sensitivity compared to WASPAM which was achieved by the following improvements: cooling of the horn antenna (which was not done for WASPAM), use of an ortho mode transducer in order to use both vertical and horizontal polarisation in the analysis and InP amplifiers cooled to $15 \mathrm{~K}$ instead of GaAs cooled to $20 \mathrm{~K}$. A more extensive description of the instrument can be found in Hallgren et al. (2010) and Hallgren (2010). A sister instrument, cWASPAM3, recently participated in an intercomparison campaign at Zugspitze Observatory where all participating instruments agreed well on their retrieved water vapour profiles (Straub et al., 2011).

The two main objectives of the new instrument were to replace the WASPAM instrument (Hartogh and Jarchow, 1995) installed 1995 and to detect and characterise the short term variations (such as tidal behaviour) of the WVMR in the polar mesosphere. Similar to its predecessor, cWASPAM observes the rotational transition of the water molecule at $22.235 \mathrm{GHz}$. The vertical and horizontal polarisation components of the signal are simultaneously analysed with two Chirp Transform Spectrometer (CTS) backends (Hartogh and Hartmann, 1990; Villanueva and Hartogh, 2004; Villanueva et al., 2006; Paganini and Hartogh, 2009). The CTS are identical and have a bandwidth of $40 \mathrm{MHz}$ which is divided into 4096 channels with a resolution of $14 \mathrm{kHz}$ each. The channels are slightly overlapping so that the effective spectral resolution becomes $10 \mathrm{kHz}$. Due to pressure broadening of the emission the narrow bandwidth acts as the practical lower boundary of the measurements (approximately $40-45 \mathrm{~km}$ ). The upper limit is set by the transition altitude where the Doppler broadening becomes more important than the pressure broadening. Typical Doppler broadening of this line is $\sim 30 \mathrm{kHz}$, well above our channel resolution. The transition for this particular line occurs at $80-85 \mathrm{~km}$. Above this altitude we can no longer resolve the vertical distribution of water vapour.

The noise temperature of each polarisation backend is on the order of $30 \mathrm{~K}$. The spectra derived from the vertical and horizontal polarisation are statistically independent so that averaging the two signals essentially doubles the integration time, or reduces the noise by $1 / \sqrt{2}$. Although the backends are identical the output differs slightly due to imperfections in the polarisation splitter (an ortho-mode transducer). Hence they are averaged by the standard way of combining two independent measurements $\left(x_{1}\right.$ and $\left.x_{2}\right)$ weighted by their respective spectral noise. This results in the equivalent single polarisation backend with a noise temperature of approximately $20 \mathrm{~K}$. Even with a moderate tropospheric transmission of $50 \%$ the high sensitivity of the instrument allows retrieval of reliable atmospheric profiles throughout most of the observable range every six hours. To study the dynamics in the lower range of the sensitive region (e.g. sudden stratospheric warmings) the integration time can be shortened to four hours.

\section{Data retrieval}

The retrieval follows the optimal estimation method (OEM) described in Rodgers (1976). It requires temperatures of the background atmosphere which are compiled by a combination of actual weather data from NCEP (McPherson et al., 1979) and the CIRA86 model (Fleming et al., 1990). During summer season the CIRA86 is modified with a falling sphere climatology for ALOMAR (Lübken, 1999). In the 
forward model we use a linear approximation of the atmosphere with 28 layers, the lowermost located at $22.5 \mathrm{~km}$ and the uppermost at $92.5 \mathrm{~km}$. Each layer is $2.5 \mathrm{~km}$ thick and no correlation between the layers is introduced mathematically (Rodgers, 1990). However, the altitude resolution of the instrument (see Fig. 1) is larger than the layer thickness in the forward model thus each layer will be affected by layers directly above and below. The OEM is a statistical method of combing two (or more) measurements in an optimal way. As the second set of measurements an estimate of a standard water vapour profile, called the a priori profile, and its associated covariance matrix, is used. This observation focuses on the short term variability and less on the absolute quantities of the water vapour and therefore a static a priori profile was used. It is a piecewise linear profile, increasing from $4 \mathrm{ppmv}$ at $20 \mathrm{~km}$ to $7.5 \mathrm{ppmv}$ at $40 \mathrm{~km}$, constant with altitude up to $65 \mathrm{~km}$ where it starts to decrease and at $90 \mathrm{~km}$ there is no water left $(0 \mathrm{ppmv})$. The same profile has been used for earlier work with WASPAM-data Seele and Hartogh (1999, 2000). An estimate of the quality of the data can be seen from the averaging kernels shown in Fig. 1. Averaging kernels are not expected to change significantly between subsequent measurements as long as the measurement itself has a reasonable signal to noise ratio. The kernels shown can therefore be assumed to be representative for the whole dataset.

Although after six hours of integration time the spectral noise is small enough to retrieve vertical profiles with well defined error bars, the signal-to-noise ratio is still not high enough to detect small tide amplitudes in the water vapour, especially in the upper mesosphere. To overcome this problem we employ a moving time-frame integration scheme. The initial six hour integration time is kept, but every single day in the month is added to the integration. This adds up to a total of $\sim 180 \mathrm{~h}$ of integration time for the each monthly time-frame spectra. The timestamp is defined as the time of the day plus/minus half the integration time. After the integration run the time-frame is shifted two hours - if the first data point was between 00:00 and 06:00 UT, the next one will be 02:00 and 08:00 UT. Thus we get 12 spectra for the monthly mean $24 \mathrm{~h}$ period. As can be seen in Fig. 1 the averaging kernels from the instrument is almost identical between 50 and $80 \mathrm{~km}$ altitude. In other words the amount of information taken from the a priori relative to the observation is very similar.

\section{Observations and analysis}

Since we only present observations from one location, the source and structure of the oscillations cannot be uniquely deduced. Although we can not conclusively attribute the detected oscillations to the solar tides we have for simplicity decided to denote the $24 \mathrm{~h}$ period oscillation as the diurnal component and the $12 \mathrm{~h}$ period oscillation as semidiurnal com-

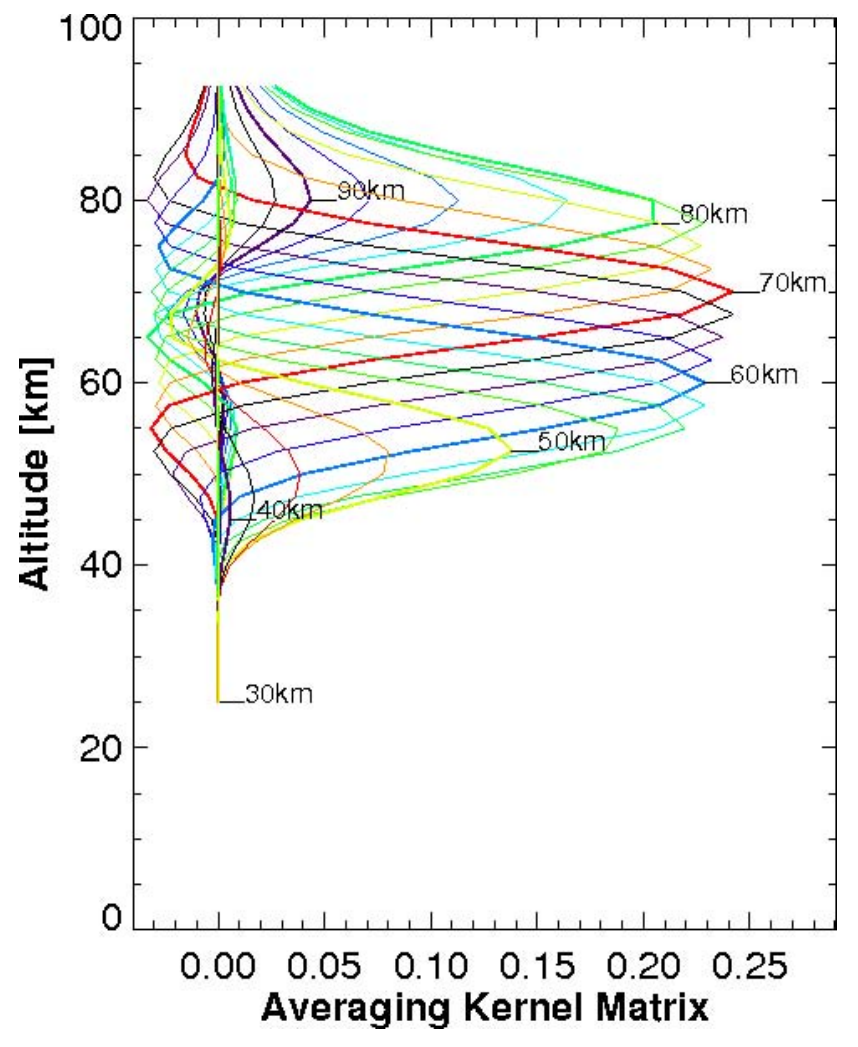

Fig. 1. Typical averaging kernels for observations of the tides. Due to the long integration time $(\approx 180 \mathrm{~h})$ the instrument is almost as sensitive at $80 \mathrm{~km}$ as at $50 \mathrm{~km}$.

ponent of the tides. To fit the observed variations a simple wave-like behaviour is assumed,

$B+\sum A_{i} \cdot \cos \left(\omega_{i}+\lambda_{i}\right)$

where $B$ denotes the background water vapour mixing ratio, $A_{i}$ is the amplitude, $\omega_{i}$ the frequency and $\lambda_{i}$ the phase offset of the tide. Initially three components where included in the fit (diurnal, semidiurnal and terdiurnal, $i=1,2,3$ ), however the terdiurnal component was found to be negligible and removed.

In Fig. 2 the WVMR from December 2008 for three different layers can be seen. The altitude difference between each layer (each subplot) is $10 \mathrm{~km}$. The solid line is the measured variability of the WVMR as a function of the local time, and the dotted line is the fit according to Eq. (1). The chosen month for Fig. 2 is arbitrary but shows a general behaviour of the variability of the retrieved volume mixing ratio. Over the course of the year the phase and amplitude is not stable but changes. The variation of the amplitude for the diurnal component can be seen in Fig. 3 and the semidiurnal component in Fig. 4. The detected amplitudes are most probably underestimated as the integration of six hours from every day in the month will smooth out peaks and hereby reduce the amplitude. 

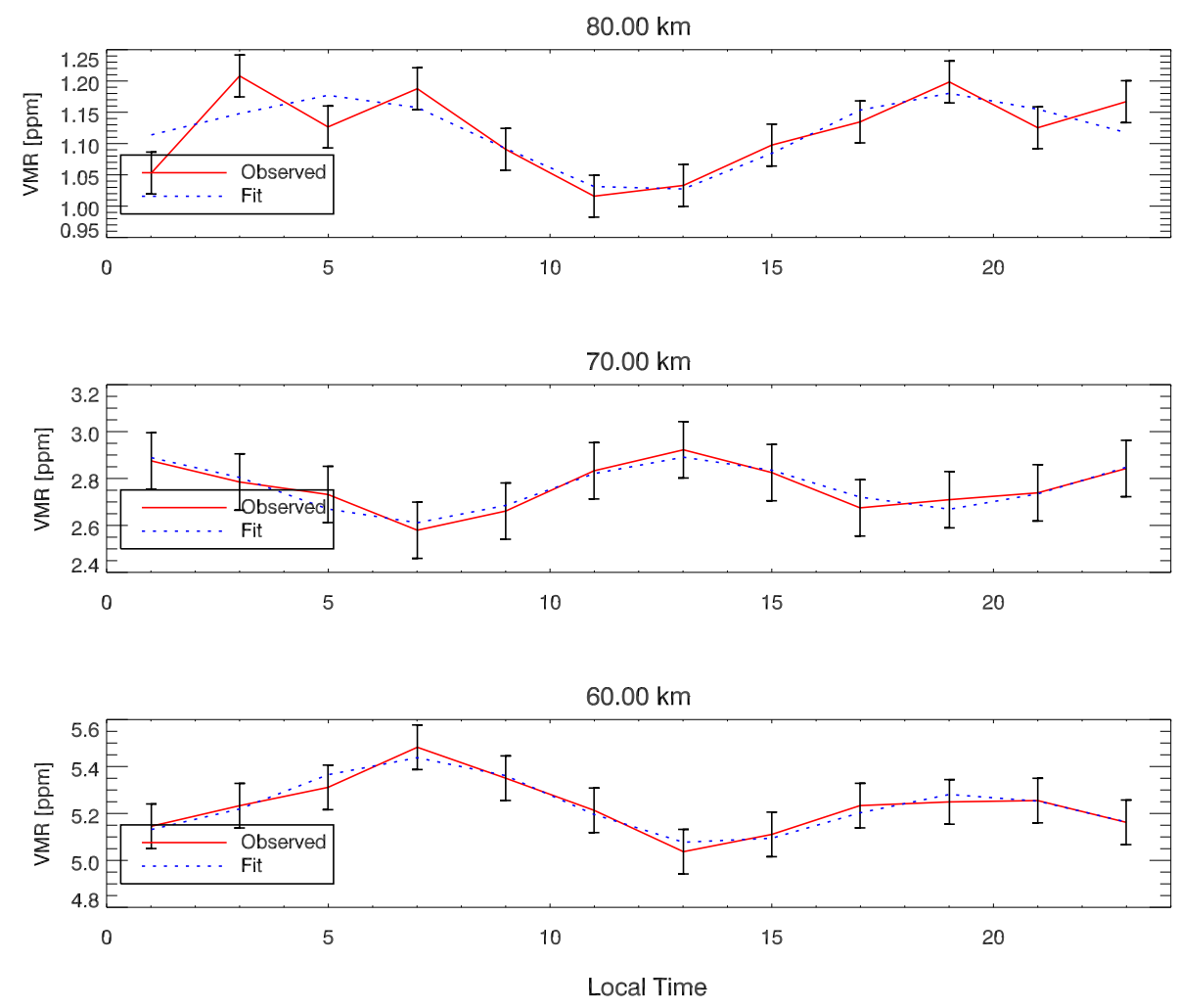

Fig. 2. The volume mixing ration as a function of local time for the eight topmost layers during December 2008. The vertical difference between each layer is $10 \mathrm{~km}$. The solid line is the measured variability and the dotted line is the fit according to Eq. (1.)

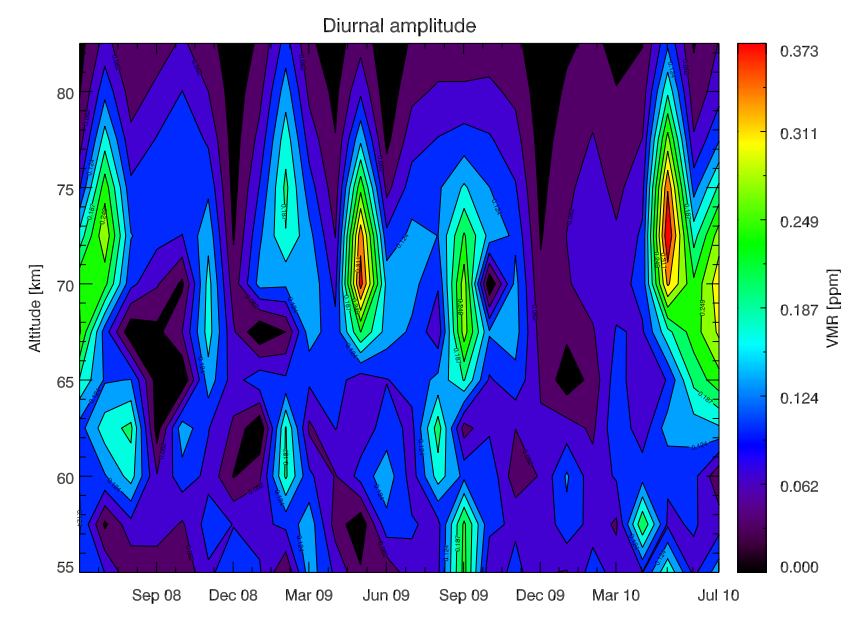

Fig. 3. A contour plot showing the variability over the dataset of the diurnal component of the fitted tide. Note the strong increase in the amplitude at each equinox.

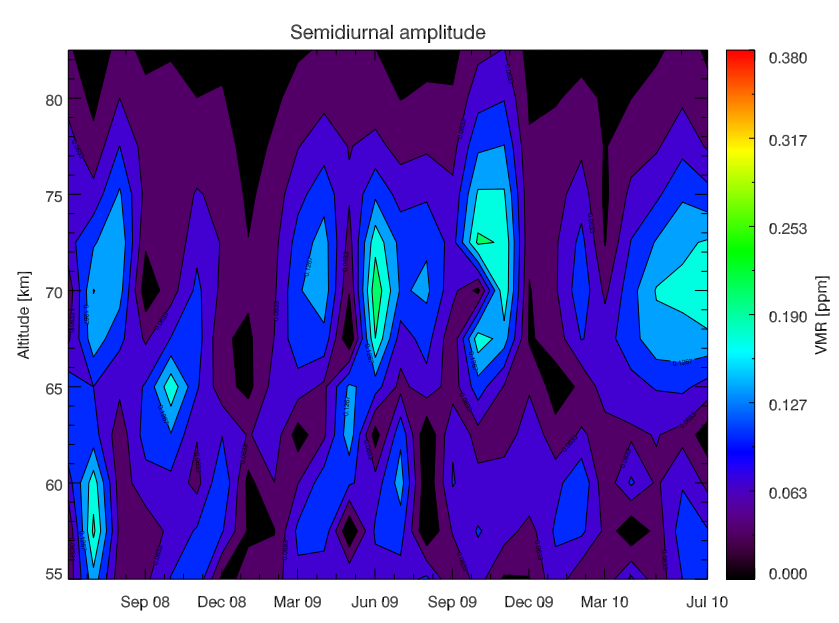

Fig. 4. As Fig. 3, but for the semidiurnal component. 


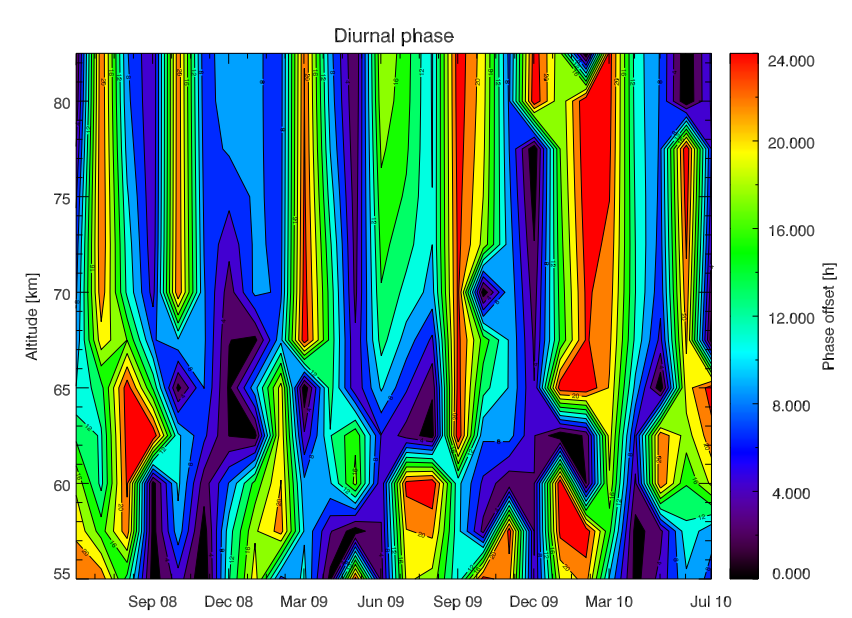

Fig. 5. The same state of affairs as Fig. 3, but showing the phase.

The amplitude of the diurnal component shows a semiannual variation, with maxima during the equinox and minima during solstice. For the semidiurnal component (Fig. 4) the picture is different with a much more complex behaviour in the measured region. Thus a larger data-set is needed to fully isolate yearly recurring features. In general the amplitude of the diurnal component is stronger than the semidiurnal component. They are however much smaller than the seasonal variability which at $70 \mathrm{~km}$ altitude varies with almost a factor of three (Seele and Hartogh, 1999).

The phases (see Figs. 5 and 6) of the observed tidal components changes over the course of the year, which also can be observed in wind fields presented in Portnyagin (2006). Similar to the theoretical results for wind and temperature fields in Forbes (1982a,b) they are relatively stable over the observed altitude with only slight variations for each time step. The semidiurnal component is however more variable than the diurnal counterpart.

\section{Discussion}

It can be seen from the averaging kernels (Fig. 1) that the atmosphere is fairly well resolved up to $80 \mathrm{~km}$. Information about the water vapour above this level can only be understood as the total column depth which is projected onto the $80 \mathrm{~km}$ layer. This could explain the sometimes irregular behaviour at this altitude. It is important to note that the measured quantity is water vapour, an atmospheric tracer. At the altitudes observed water vapour has a lifetime on the order of days and longer, and we can therefore exclude any tidal influence in the water vapour production (or destruction). The observed variability is therefore assumed to be caused by tidal behaviour in the transport mechanisms. Tidal behaviour has been observed in all wind fields (zonal, meridional and vertical) which implies that the resulting tidal transport vector

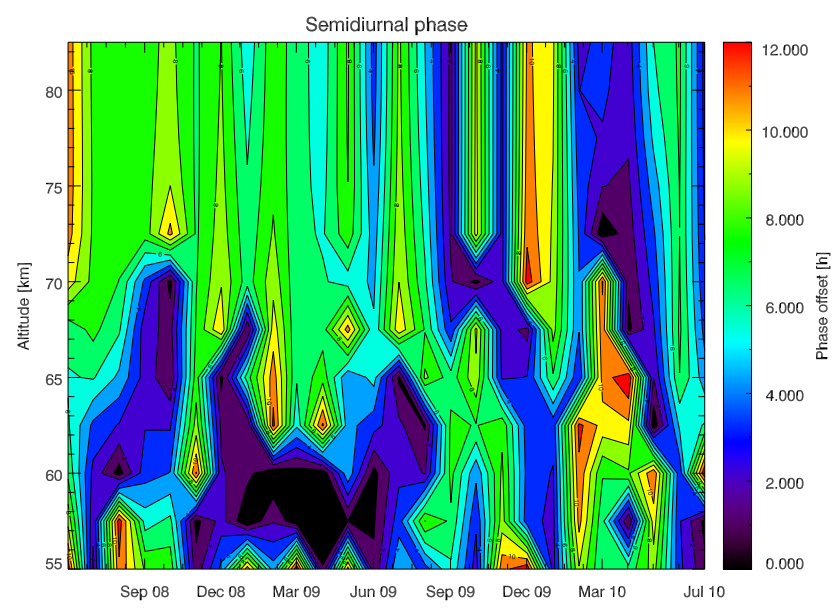

Fig. 6. As Fig. 4, but showing the phase.

for a tracer would be the sum of the components and as expected the observed behaviour does not follow any of the wind fields.

The seasonal behaviour of the diurnal tide with maxima during equinoxes has been noted by other groups: in global observations of winds from the UARS (Upper Atmosphere Research Satellite) (Hays et al., 1994), as well as ground based radar observations (Vincent et al., 1988) and models (McLandress, 1997). The behaviour is further investigated in two papers by McLandress (2002a,b). In the first paper it is ruled out that the seasonal variation is caused by gravity or planetary wave-tide interactions. Instead, as is shown in the second paper, it is most probably a combination of tidal heating and the zonal mean winds. The model produces qualitatively similar results for both the heating and the mean winds and both effects are therefore used to explain the variation. The effect of the tidal heating can be understood by decomposition of the tidal temperature into its Hough modes. The $(1,1)$ and $(1,2)$ mode are the two dominant vertically propagating modes and due to their different vertical wavelengths constrictive and destructive interference occurs depending on altitude with the resulting annual variation. It should however be noted that the result from these model calculations have not been verified for the high latitudes where the current observations take place.

The retrieval is sensitive to changes in the temperature of the background atmosphere and oscillating temperatures could introduce artifacts in the observations. Currently, the background atmosphere used has a time-step of one day, i.e. each $24 \mathrm{~h}$ period is retrieved with the same background. In order to quantify the impact of unaccounted thermal oscillations a sine-like variation of the temperature was modeled and thereafter retrieved with a static background. Oscillations with an amplitude weaker than $\pm 5 \mathrm{~K}$ (at $75 \mathrm{~km}$ ) were found to be negligible. Recent LIDAR results from 
ALOMAR (Lübken et al., 2011) indicate thermal tides of a similar magnitude approximately $10 \mathrm{~km}$ higher, in the region between 85 and $96 \mathrm{~km}$, which would indicate smaller amplitudes at $75 \mathrm{~km}$. It should also be noted that results from GSWM-09 (Zhang et al., 2010a,b) indicate much weaker thermal tides in this region $( \pm 1 \mathrm{~K})$. We therefore assume that the unaccounted thermal tides do not introduce any large artifacts in the data. Oscillations in the background atmosphere do nevertheless introduce a certain small error in the retrieval. Thus a background atmosphere with higher timeresolution would be desirable for a better understanding of the tidal transport mechanisms in the middle atmosphere.

\section{Conclusions}

A new radiometer has been installed at the ALOMAR observatory. The sensitivity has been greatly improved compared to the older WASPAM instrument, which allows for a higher temporal and vertical resolution. We have looked for tidal signatures in data retrieved since May 2008 by applying a moving time-frame integration scheme. A harmonic approach with a diurnal and semidiurnal component was thereafter used in order to fit the resulting variability in water vapour levels. The observations indicates that the diurnal amplitude component in water vapour has a maximum around the equinoxes which is consistent with model predictions for tidal behaviour in winds. The fit of the semidiurnal component on the other hand is less clear and no obvious pattern could be revealed with the current dataset. In order to better understand its behaviour more data is needed.

Acknowledgements. This work was supported by the German Research Community, DFG, grant HA-3261/7-1. The authors would like to thank the staff at ALOMAR for their support in maintaining the instrument and the Atmospheric and Dynamics branch at NASA Goddard Space Center for making the NCEP data available through their automailer system.

The service charges for this open access publication have been covered by the Max Planck Society.

Edited by: S. Buehler

\section{References}

Brasseur, G. and Solomon, S.: Aeronomy of the middle atmosphere, D. Reidel Publishing Company, 1998.

Fleming, E. L., Chandra, S., Barnett, J., and Corney, M.: Zonal mean temperature, pressure, zonal wind and geopotential height as functions of latitude, Adv. Space Res., 10, 11-59, doi:10.1016/0273-1177(90)90386-E, 1990.

Forbes, J. M.: Atmospheric tides. I - Model description and results for the solar diurnal component, J. Geophys. Res., 87, 52225241, doi:10.1029/JA087iA07p05222, 1982a.
Forbes, J. M.: Atmospheric tides. II - The solar and lunar semidiurnal components, J. Geophys. Res., 87, 5241-5252, doi:10.1029/JA087iA07p05241, 1982 b.

Forbes, J. M. and Wu, D.: Solar Tides as Revealed by Measurements of Mesosphere Temperature by the MLS Experiment on UARS, Journal of Atmospheric Sciences, 63, 1776-1797, doi:10.1175/JAS3724.1, 2006.

Fritts, D. C. and Vincent, R. A.: Mesospheric momentum flux studies at Adelaide, Australia - Observations and a gravity wave-tidal interaction model, Journal of Atmospheric Sciences, 44, 605-619, doi:10.1175/15200469(1987)044;0605:MMFSAA ¿2.0.CO;2, 1987.

Haefele, A., Hocke, K., Kämpfer, N., Keckhut, P., Marchand, M., Bekki, S., Morel, B., Egorova, T., and Rozanov, E.: Diurnal changes in middle atmospheric $\mathrm{H}_{2} \mathrm{O}$ and $\mathrm{O}_{3}$ : Observations in the Alpine region and climate models, J. Geophys. Res.-Atmos., 113, D17303, doi:10.1029/2008JD009892, 2008.

Hallgren, K.: Mesospheric water vapor - Variability at different timescales observed by ground-based microwave spectroscopy, Ph.D. Thesis, Universität Rostock, 2010.

Hallgren, K., Hartogh, P., and Jarchow, C.: A New, Highperformance, Heterodyne Spectrometer for Ground-based Remote Sensing of Mesospheric Water Vapour, World Scientific Publishing Co., 19, 569-578, 2010.

Hartogh, P. and Hartmann, G. K.: A high-resolution chirp transform spectrometer for microwave measurements, Meas. Sci. Technol., 1, 592-595, 1990.

Hartogh, P. and Jarchow, C.: Groundbased detection of middle atmospheric water vapor, in: Global Process Monitoring and Remote Sensing of Ocean and Sea Ice, EUROPTO-Series 2586, 188-195, SPIE, Bellingham, 1995.

Hartogh, P., Sonnemann, G. R., Grygalashvyly, M., Song, L., Berger, U., and Lübken, F.: Water vapor measurements at ALOMAR over a solar cycle compared with model calculations by LIMA, J. Geophys. Res.-Atmos., 115, D00I17, doi:10.1029/2009JD012364, 2010.

Hays, P. B., Wu, D. L., and The Hrdi Science Team: Observations of the Diurnal Tide from Space., Journal of Atmospheric Sciences, 51, 3077-3093, doi:10.1175/15200469(1994)051;3077:OOTDTF; 2.0.CO;2, 1994.

Lübken, F.-J.: Thermal structure of the arctic summer mesosphere, J. Geophys. Res., 104, 9135-9150, doi:10.1029/1999JD900076, 1999.

Lübken, F.-J., Höffner, J., Viehl, T. P., Kaifler, B., and Morris, R. J.: First measurements of thermal tides in the summer mesopause region at Antarctic latitudes, 38, L24806, doi:10.1029/2011GL050045, 2011.

Manson, A. H., Luo, Y., and Meek, C.: Global distributions of diurnal and semi-diurnal tides: observations from HRDIUARS of the MLT region, Ann. Geophys., 20, 1877-1890, doi:10.5194/angeo-20-1877-2002, 2002a.

Manson, A. H., Meek, C., Hagan, M., Koshyk, J., Franke, S., Fritts, D., Hall, C., Hocking, W., Igarashi, K., MacDougall, J., Riggin, D., and Vincent, R.: Seasonal variations of the semi-diurnal and diurnal tides in the MLT: multi-year MF radar observations from $2-70^{\circ} \mathrm{N}$, modelled tides (GSWM, CMAM), Ann. Geophys., 20, 661-677, doi:10.5194/angeo-20-661-2002, 2002b.

McLandress, C.: Seasonal variability of the diurnal tide: Results from the Canadian middle atmosphere general circulation model, 
J. Geophys. Res., 102, 29747-29764, doi:10.1029/97JD02645, 1997.

McLandress, C.: The Seasonal Variation of the Propagating Diurnal Tide in the Mesosphere and Lower Thermosphere. Part I: The Role of Gravity Waves and Planetary Waves., Journal of Atmospheric Sciences, 59, 893-906, doi:10.1175/15200469(2002)059;0893:TSVOTP ¿2.0.CO;2, 2002a.

McLandress, C.: The Seasonal Variation of the Propagating Diurnal Tide in the Mesosphere and Lower Thermosphere. Part II: The Role of Tidal Heating and Zonal Mean Winds., Journal of Atmospheric Sciences, 59, 907-922, doi:10.1175/15200469(2002)059;0907:TSVOTP ¿2.0.CO;2, 2002 b.

McPherson, R. D., Bergman, K. H., Kistler, R. E., Rasch, G. E., and Gordon, D. S.: The NMC Operational Global Data Assimilation System, Mon. Weather Rev., 107, 1445-1461, doi:10.1175/1520-0493(1979)107;1445:TNOGDA $i 2$ 2.0.CO;2, 1979.

Nedoluha, G. E., Bevilacqua, R. M., Michael Gomez, R., Waltman, W. B., Hicks, B. C., Thacker, D. L., and Andrew Matthews, W.: Measurements of water vapor in the middle atmosphere and implications for mesospheric transport, J. Geophys. Res., 101, 21183-21194, doi:10.1029/96JD01741, 1996.

Paganini, L. and Hartogh, P.: Analysis of nonlinear effects in microwave spectrometers, J. Geophys. Res.-Atmos., 114, D13305, doi:10.1029/2008JD011141, 2009.

Portnyagin, Y.: A review of mesospheric and lower thermosphere models, Adv. Space Res., 38, 2452-2460, doi:10.1016/j.asr.2006.04.030, 2006.

Portnyagin, Y. I., Solovjova, T. V., Makarov, N. A., Merzlyakov, E. G., Manson, A. H., Meek, C. E., Hocking, W., Mitchell, N., Pancheva, D., Hoffmann, P., Singer, W., Murayama, Y., Igarashi, K., Forbes, J. M., Palo, S., Hall, C., and Nozawa, S.: Monthly mean climatology of the prevailing winds and tides in the Arctic mesosphere/lower thermosphere, Ann. Geophys., 22, 33953410, doi:10.5194/angeo-22-3395-2004, 2004.

Rodgers, C. D.: Retrieval of Atmospheric Temperature and Composition From Remote Measurements of Thermal Radiation, Rev. Geophys. Space Ge., 14, 609-624, doi:10.1029/RG014i004p00609, 1976.

Rodgers, C. D.: Characterization and error analysis of profiles retrieved from remote sounding measurements, J. Geophys. Res., 95, 5587-5595, doi:10.1029/JD095iD05p05587, 1990.
Seele, C. and Hartogh, P.: Water vapor of the polar middle atmosphere: Annual variation and summer mesosphere conditions as observed by ground-based microwave spectroscopy, Geophys. Res. Lett., 26, 1517-1520, 1999.

Seele, C. and Hartogh, P.: A case study on middle atmospheric water vapor transport during the February 1998 stratospheric warming, Geophys. Res. Lett., 26, 3309-3312, 2000.

Sonnemann, G. R., Hartogh, P., Grygalashvyly, M., Li, S., and Berger, U.: The quasi 5-day signal in the mesospheric water vapor concentration at high latitudes in 2003-a comparison between observations at ALOMAR and calculations, J. Geophys. Res.-Atmos., 113, D04101, doi:10.1029/2007JD008875, 2008.

Straub, C., Murk, A., Kämpfer, N., Golchert, S. H. W., Hochschild, G., Hallgren, K., and Hartogh, P.: ARIS-Campaign: intercomparison of three ground based $22 \mathrm{GHz}$ radiometers for middle atmospheric water vapor at the Zugspitze in winter 2009, Atmos. Meas. Tech., 4, 1979-1994, doi:10.5194/amt-4-1979-2011, 2011.

Villanueva, G., and Hartogh, P.: The High Resolution Chirp Transform Spectrometer for the Sofia-Great Instrument, Exp. Astron., 18, 77-91, doi:10.1007/s10686-005-9004-3, 2004.

Villanueva, G. L., Hartogh, P., and Reindl, L.: A digital dispersive matching network for SAW devices in chirp transform spectrometers, IEEE T. Microw. Theory, 54, 1415-1424, doi:10.1109/TMTT.2006.871244, 2006.

Vincent, R. A., Tsuda, T., and Kato, S.: A comparative study of mesospheric solar tides observed at Adelaide and Kyoto, J. Geophys. Res., 93, 699-708, doi:10.1029/JD093iD01p00699, 1988.

Wang, D. and Fritts, D. C.: Evidence of Gravity Wave-Tidal Interaction Observed near the Summer Mesopause at Poker Flat, Alaska., Journal of Atmospheric Sciences, 48, 572-583, doi:10.1175/1520-0469(1991)048;0572:EOGWIO ¿2.0.CO;2, 1991.

Zhang, X., Forbes, J. M., and Hagan, M. E.: Longitudinal variation of tides in the MLT region: 1 . Tides driven by tropospheric net radiative heating, J. Geophys. Res.-Space, 115, A06316, doi:10.1029/2009JA014897, 2010a.

Zhang, X., Forbes, J. M., and Hagan, M. E.: Longitudinal variation of tides in the MLT region: 2. Relative effects of solar radiative and latent heating, J. Geophys. Res.-Space, 115, A06317, doi:10.1029/2009JA014898, 2010b. 